\title{
Modelação de Relevo e Obtenção de Parâmetros Fisiográficos na Bacia do Rio Cuiabá
}

\author{
Peter Zeilhofer \\ Depto. de Engenharia Sanitária e Ambiental, UFMT \\ 78060-900 Cuiabá, MT \\ Recebido: 28/08/00 - revisão: 09/11/00 - aceito: 28/05/01
}

\section{RESUMO}

Neste estudo foi avaliada a aplicabilidade de dados plano-altimétricos provenientes dos mapas topográficos brasileiros da escala 1:100.000 para a elaboração de modelos numéricos de terreno e parâmetros fisiográficos derivados, tais como declividade e fluxo superficial acumulado. Através de comparações com modelagens baseadas em informações de alta resolução (1:25.000) foi estudada a influência de diferentes técnicas de triangulação/interpolação; da utilização da rede hidrográfica digitalizada na modelação; e da resolução vertical dos dados plano-altimétricos, na qualidade dos produtos gerados.

Palavras-chave: modelo; relevo; Cuiabá.

\section{INTRODUÇÃO}

A interpolação e o processamento de modelos numéricos de terreno (MNT) são operações fundamentais para a caraterização do relevo de bacias hidrográficas e suas redes de drenagem. Parâmetros fisiográficos derivados dos MNTs tais como a declividade, direção de escoamento, fluxo superficial acumulado ou a rede de drenagem e suas características podem ser utilizados como dados de entrada em modelos concentrados e distribuídos da quantidade e qualidade da água (Olivera et al., 1998; Mendes, 1996).

Em grande parte do território nacional os mapas topográficos da escala 1:100.000 com curvas de nível de uma eqüidistância de $40 \mathrm{~m}$ (folhas elaboradas pelo Ministério do Exército - DSG) ou $50 \mathrm{~m}$ (folhas elaboradas pelo IBGE - Superintendência de Cartografia) são as mais detalhadas informações disponíveis sobre o relevo. Porém, na maioria dos órgãos públicos a falta de equipamento apropriado impossibilita a geração de MNTs mais detalhados, elaborados através de métodos fotogramétricos utilizando fotos aéreas e imagens de satélites ou através de Interferometria a partir de dados de sistemas imageadores de radar (p. ex. ERS1/2). Em função dos altos custos, a aquisição de informações altimétricas por trabalho de campo é restrita a estudos locais em grandes escalas.
Em vista da bem sucedida missão topográfica do ônibus espacial "Space Shuttle Topographic Mission - SRTM" (DLR, 2000) para um mapeamento completo do relevo do mundo através de interferometria "one-pass", a importância das folhas topográficas 1:100.000 como fonte de informação planoaltimétrica tende a diminuir. Pergunta-se entretanto, se estes MNTs devem ser submetidos a um pósprocessamento utilizando a rede hidrográfica digitalizada para garantir sua aplicabilidade para estudos hidrológicos.

Vários estudos salientam a grande influência da qualidade dos dados primários (curvas de nível, pontos cotados) na modelação de MNTs e produtos derivados. Wise (1998) constata que pequenos erros na elevação podem causar grandes erros em parâmetros derivados tais como declividade e exposição do relevo. Um erro vertical de somente $0,5 \mathrm{~m}$ aplicado a um MNT da escala 1:24.000 com uma resolução horizontal de $30 \mathrm{~m}$, resulta em modificações significativas na rede de drenagem simulada, com expressivas fragmentações dos cursos da água (Lee et al., 1992; Lee, 1996). A qualidade dos parâmetros fisiográficos derivados depende também da qualidade do processo/método da geração do MNT que por sua vez deve determinar a escala e resolução do modelo. Critérios para a classificação da qualidade de MNTs em diferentes níveis (level 1 a 4) foram estabelecidos pelo U.S. Geological Survey (USGS, 1997). 
Não existe, entretanto, uma avaliação unânime nas comparações da qualidade de MNTs e produtos derivados, modelados a partir de informações plano-altimétricas de diferentes acurácias e resoluções. Wang e Yin (1997) observam uma boa correspondência entre as redes de drenagem extraídas de MNTs da escala 1:24.000 (resolução horizontal da grade $30 \mathrm{~m}$ ) e 1:250.000 (resolução horizontal da grade $92,5 \mathrm{~m}$ ). Ao contrário, MüllerWohlfeil et al. (1996) observam mudanças significativas na distribuição do Índex Topográfico $\ln (\mathrm{a} /$ $\tan (\beta)$ ) calculado com TOPMODEL - um parâmetro que considera a área drenada (a) acima de um ponto observado e a inclinação local $(\tan (\beta))$ - em função da resolução espacial do MNT utilizado.

Para a modelagem da superfície do terreno, as informações plano-altimétricas das folhas topográficas (isolinhas, pontos cotados) alimentam geralmente um algoritmo de triangulação. Outros métodos permitem a interpolação de MNTs matriciais utilizando diretamente as informações planoaltimétricas (Hutchinson, 1989). Na maioria das implementações podem ser consideradas linhas de quebra do relevo, tais como escarpas ou a rede hidrográfica. Para o processamento consecutivo, as grades triangulares são transformadas através de um interpolador linear ou quíntico em grades retangulares. $\mathrm{O}$ formato matricial do MNT resultante é computacionalmente mais apropriado para a criação de produtos derivados tais como planos de informação (PIs) da declividade e exposição (Guth, 1995), a delineação automatizada da rede de drenagem, de limites de bacias hidrográficas, e a determinação do fluxo acumulado do escoamento superficial (Quinn et al., 1992).

Módulos de triangulação e interpolação estão disponíveis em uma vasta gama de softwares de geoprocessamento. Entretanto, implementações de métodos tradicionais de triangulação e interpolação são incapazes de considerar as orientações das linhas de quebra, como a direção do escoamento no caso da rede de drenagem. Também faltam em alguns softwares módulos para a remoção de depressões locais, artificialmente criadas pelos algoritmos. Portanto, a utilização de produtos derivados pode introduzir erros na modelação distribuída de vazão ou de aportes poluidores por fontes difusas. O fluxo superficial acumulado simulado pode ser interrompido na direção do escoamento real e/ou linhas de drenagem desviadas para outras sub-bacias.

Considerando as influências de algoritmos e dados básicos na criação de MNTs e produtos de- rivados, serão discutidos três itens principais relacionados a utilização de MNTs para aplicações hidrológicas:

- Influência de diferentes algoritmos de triangulação/interpolação na modelação do relevo e de produtos derivados;

- Importância da utilização de PIs da rede hidrográfica como "linhas de quebra" na modelação de MNTs;

- Influência da resolução vertical dos dados plano-altimétricos básicos na qualidade dos modelos gerados.

\section{MATERIAIS E MÉTODOS}

\section{Área de estudo}

Foram utilizados dados da bacia do alto e médio rio Cuiabá, situada no sul do Estado de Mato Grosso, entre $14^{\circ} 15^{\prime}$ e $16^{\circ} 10^{\prime}$ de latitude sul e de $54^{\circ} 45^{\prime}$ e $56^{\circ} 55^{\prime}$ longitude oeste com uma extensão de cerca de $29.000 \mathrm{~km}^{2}$ (Figura 1). Grande parte da bacia hidrográfica do rio Cuiabá como o Planalto dos Guimarães e o aplanamento da Baixada Cuiabana é levemente ondulada. Um relevo mais acentuado é encontrado na região das escarpas da Chapada de Guimarães e na Província Serrana no norte e oeste da bacia.

MNTs foram interpolados utilizando os dados plano-altimétricos de 19 folhas topográficas

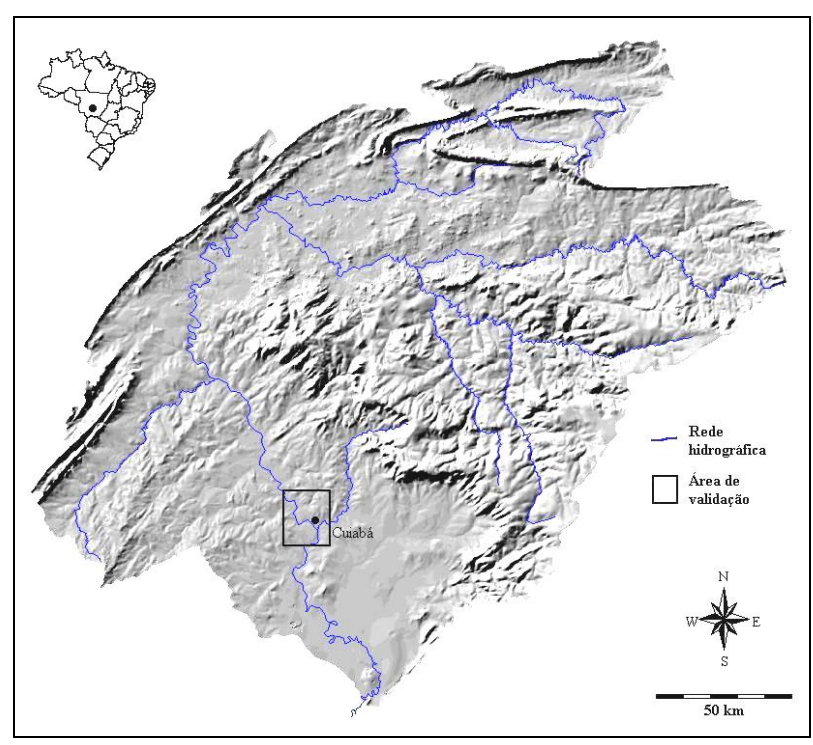

Figura 1. Imagem sombreada do MNT da bacia hidrográfica do rio Cuiabá com área de validação. 
(curvas de níveis, pontos cotados, rede de drenagem) da escala 1:100.000, sendo 14 folhas com equidistâncias das curvas de nível de $40 \mathrm{~m}$ (inclusive na área de validação), e 05 folhas, na parte setentrional da área de estudo, de $50 \mathrm{~m}$.

Para a validação foi elaborado um MNT baseado no mapa plano-altimétrico 1:25.000 dos perímetros urbanos de Cuiabá e Várzea Grande, com eqüidistância das curvas de nível de $10 \mathrm{~m}$ (MNT_25). Observa-se que esta forma de validação foi efetuada devido a falta de equipamento apropriado para a aquisição de dados independentes por aerofotogrametria ou GPS diferencial. A área de validação com uma extensão de $270 \mathrm{~km}^{2} \mathrm{faz}$ parte do embasamento do grupo Cuiabá, de relevo suavemente ondulado com uma faixa de elevação entre $146 \mathrm{~m}$ e $266 \mathrm{~m}$.

\section{Software utilizado}

Para a elaboração dos MNTs de grade retangular foram utilizados os módulos Createtin-Tinlattice e Topogrid do software Arc/Info 7.2.1 (ESRI, 1998a). Createtin é uma implementação da triangulação de Delaunay que permite a consideração de linhas de quebra. Tinlattice é um interpolador que transforma o modelo de grades irregulares numa grade regular (Lattice). Neste modelo de dados o valor da altitude não é associado às células inteiras mas aos pontos centrais, fato que melhora a qualidade das modelações do terreno e de parâmetros fisiográficos derivados (Wise, 1998).

Topogrid é uma implementação de um interpolador desenvolvido por Hutchinson (1989) criado para obter uma melhor representação da característica anisotrópica (ou direcional) do relevo. Na sua atualização (Hutchinson, 1996), o algoritmo do conceito "localmente adaptado" (locally adaptive) modela o terreno iterativamente com resoluções consecutivas crescentes, até chegar na sua resolução final. Topogrid permite imposição das linhas de drenagem que garante a integridade do declive do terreno na direção do escoamento superficial. Através da definição de tolerâncias horizontais e verticais podem ser removidos pixels que interrompem o fluxo ao longo da rede de drenagem digitalizada ou que são identificadas como depressões fechadas.

\section{Definição da resolução horizontal dos planos de informação elaborados}

Gyasi-Agyei et al. (1995) mostram a influência da resolução horizontal (tamanho das células) de MNTs na modelação de parâmetros fisiográficos derivados. A definição de uma resolução apropriada para um MNT deve ser baseada na resolução e acurácia das informações plano-altimétricas originárias e pelo próprio relevo. Neste contexto, Galant e Hutchinson (1996), propõem uma modelação do relevo em variadas escalas, isso em função das diferentes situações topográficas.

Os padrões sobre a qualidade de mapas topográficos e MNTs norte-americanos formulados pelo U.S. Geological Survey (USGS, 1997; 1999) foram utilizados como indicativo de qual resolução horizontal deve ser escolhida para MNTs derivados das folhas topográficas 1:100.000.

Os MNTs de dois segundos (MNT de 2") com uma resolução horizontal de cerca de 92,5 m são baseados nos dados plano-altimétricos dos mapas topográficos 1:250.000, cada folha possuindo, em função do relevo, uma resolução vertical de $30,5 \mathrm{~m}, 15,2 \mathrm{~m}$ ou $6,1 \mathrm{~m}$. Nas exigências formuladas pelo USGS, $90 \%$ de um conjunto de elevações medidas deve ter um erro menor do que a metade da resolução vertical das isolinhas (USGS, 1999).

Uma sobreposição das curvas de nível rasterizadas do mapa 1:100.000 da área de validação com um MNT baseado na planta urbana 1:25.000 mostra que cerca de $63,5 \%$ dos pontos observados possuem um erro vertical superior a 3,0 $\mathrm{m}, 33,5 \%$ um erro maior que $7,6 \mathrm{~m}$ e $5,9 \%$ um erro maior que 15,2 m. Com estes erros, o mapa 1:100.000 avaliado não se encaixa nos padrões de qualidade dos mapas norte-americanos 1:250.000 de resolução vertical de 15,2 m, que é utilizada em regiões de relevo ondulado, similar à área de estudo. Em conseqüência, os modelos foram interpolados com uma resolução horizontal de 150 m, uma redução substancial quando comparada à resolução horizontal de 92,5 m dos MNTs de 2".

Os MNTs e parâmetros fisiográficos de toda a bacia foram recortados conforme os limites dos PIs provenientes da planta urbana 1:25.000. Para evitar erros de interpolação nas margens do MNT baseado na planta urbana (MNT_top_25), a área de validação foi reduzida para uma extensão menor que a folha da planta urbana.

\section{Avaliação da incerteza}

A Tabela 1 representa um sumário dos dados plano-altimétricos, MNTs e parâmetros fisiográficos derivados utilizados nas avaliações. Todos os PIs citados são arquivos matriciais recortados 
Tabela 1. Dados plano-altimétricos, MNTs e parâmetros fisiográficos derivados utilizados para avaliação.

\begin{tabular}{|c|c|c|}
\hline $\begin{array}{l}\text { Dados plano-altimétricos, MNTs e parâmetros fisiográficos } \\
\text { considerados nas avaliações }\end{array}$ & Abreviação & Unidade \\
\hline $\begin{array}{l}\text { Elevação das células ao longo das curvas (cur) de nível e nos } \\
\text { pontos cotados (cot) da planta 1:25.000 }\end{array}$ & Cur-Cot_25 & $\mathrm{m}$ \\
\hline Rede de drenagem (drenag) dos mapas 1:100.000 & Drenag_100 & - \\
\hline $\begin{array}{l}\text { Modelos Numéricos de Terreno (MNT) baseados nos dados } \\
\text { plano-altimétricos dos mapas 1:100.000 e 1:25.000, através dos } \\
\text { algoritmos Topogrid (top) ou Createtin-Tinlattice (tin), com (c) e } \\
\text { sem (s) consideração da rede hidrográfica (depressões fechadas } \\
\text { eliminadas em todos os MNTs) }\end{array}$ & $\begin{array}{l}\text { MNT_100_top_c } \\
\text { MNT_100_tin_c } \\
\text { MNT_100_tin_s } \\
\text { MNT_25_top_c } \\
\text { MNT_25_tin_c } \\
\text { MNT_25_tin_s }\end{array}$ & $\mathrm{m}$ \\
\hline Declividade (Dec) extraída dos diferentes MNTs & $\begin{array}{l}\text { Dec_100_top_c } \\
\text { Dec_25_top_c }\end{array}$ & $\%$ \\
\hline $\begin{array}{l}\text { Rede de drenagem (Dre), calculada através dos PIs do fluxo } \\
\text { superficial acumulado }\end{array}$ & $\begin{array}{l}\text { Dre_100_top_c } \\
\text { Dre_100_tin_c }\end{array}$ & - \\
\hline $\begin{array}{l}\text { Fluxo superficial acumulado (Fac), calculado através dos PIs da } \\
\text { direção do escoamento }\end{array}$ & $\begin{array}{l}\text { Fac_100_top_c } \\
\text { Fac_100_tin_s }\end{array}$ & $\begin{array}{l}\text { Número de } \\
\text { células }\end{array}$ \\
\hline
\end{tabular}

conforme a extensão da área de validação. Cur-Cot_25 é um PI rasterizado das curvas de nível e pontos cotados provenientes da planta urbana 1:25.000. Os PIs de declividade (Dec_100_top_c, Dec_25_top_c) são diretamente calculados a partir dos MNTs, considerando a diferença máxima da altitude entre uma célula e seus vizinhos numa janela $3 \times 3$. A rede de drenagem e o fluxo superficial acumulado são determinados através da direção do escoamento. Mesmo sendo disponível um PI da rede hidrográfica, uma simulação da mesma pode ser valiosa, considerando que os rios de primeira ordem (inicialização da erosão) não são sempre corretamente representados através de métodos de fotointerpretação (Wang e Yin, 1997).

Os algoritmos implementados em Arc/Info para determinação da direção do escoamento e fluxo superficial acumulado são apresentados em Jenson e Domingue (1988) e foram classificados por Wood (1996) como técnicas geométricas, globais, exatas, indiretas e sistemáticas. A rede de drenagem é definida arbitrariamente através de um valor limite (threshold) do fluxo superficial acumulado.

Wood (1996) dá uma descrição completa de métodos para a quantificação de incertezas em MNTs. Descrições dos momentos tais como a média e o desvio padrão, erro médio quadrático e os histogramas (Wang e Yin, 1997) são os primeiros indicativos da acurácia de modelos e parâmetros fisiográficos a serem avaliados. Wood (1996) salienta a importância da visualização para uma avaliação de incertezas em MNTs. A distribuição espacial de erros pode ser analisada através do cálculo de "Imagens de Diferença" entre um MNT de referência e o MNT a ser avaliado.

A Tabela 2 mostra os objetivos das análises elaboradas, os respectivos PIs utilizados e os métodos aplicados para avaliação. Para avaliar a influência dos algoritmos de triangulação/interpolação na qualidade dos MNTs, dois modelos elaborados com os algoritmos Createtin-Tinlattice e Topogrid (MNT_100_tin_c, MNT_100_top_c) foram comparados com as elevações dos pixels ao longo das curvas de nível e nos pontos cotados da planta 1:25.000 (Cur-Cot_25). Foram avaliadas também as redes de drenagem e os fluxos superficiais acumulados simulados em cada caso.

A importância da rede de drenagem como plano de informação para a criação de MNTs "hidrologicamente" corretos, foi verificada através dos erros médios quadráticos de dois MNTs e a comparação dos fluxos superficiais acumulados, simulados com base nos modelos MNT_100_top_c e MNT_100_top_s. Esta avaliação tem sobretudo relevância tendo em vista uma aplicabilidade imediata dos MNTs provenientes da missão SRTM para estudos hidrológicos. 
Tabela 2. Planos de informação e métodos utilizados para os diferentes objetivos de avaliação.

\begin{tabular}{|c|c|c|}
\hline $\begin{array}{l}\text { Objetivo: Análise da } \\
\text { influência }\end{array}$ & MNTs e parâmetros comparados & Métodos para validação \\
\hline \multirow{3}{*}{$\begin{array}{l}\text { de diferentes algoritmos } \\
\text { de triangulação / } \\
\text { interpolação nos MNTs e } \\
\text { parâmetros derivados }\end{array}$} & $\begin{array}{l}\text { MNT_100_top_c, MNT_100_tin_c, } \\
\text { Cur-Cot_25; }\end{array}$ & $\begin{array}{l}\text { Média, mínimo, máximo, erro máximo, erro } \\
\text { médio quadrático, histogramas, visualização } \\
\text { tridimensional }(3 \mathrm{~d})\end{array}$ \\
\hline & $\begin{array}{l}\text { Dre_100_top_c, Dre_100_tin_c, } \\
\text { Drenag_100; }\end{array}$ & Visualização 3d, comprimentos das redes \\
\hline & Fac_100_top_c, Fac_100_tin_c; & Visualização 3d \\
\hline da rede hidrográfica como & MNT_100_top_s, MNT_100_top_c & Erro médio quadrático \\
\hline $\begin{array}{l}\text { "linhas de quebra" na } \\
\text { elaboração de MNTs }\end{array}$ & Fac_100_top_c, Fac_100_top_s; & Visualização \\
\hline \multirow{3}{*}{$\begin{array}{l}\text { da resolução vertical dos } \\
\text { dados plano-altimétricos } \\
\text { na qualidade dos MNTs e } \\
\text { produtos derivados }\end{array}$} & MNT_100_top_c, MNT_25_top_c; & $\begin{array}{l}\text { Média, mínimo, máximo, erro máximo, } \\
\text { erro médio quadrático, visualização 3d, } \\
\text { sobreposição }\end{array}$ \\
\hline & Dec_100_top_c, Dec_25_top_c; & Histogramas \\
\hline & Fac_100_top_c, Fac_25_top_c; & Histogramas, sobreposição \\
\hline
\end{tabular}

A influência da resolução vertical dos dados plano-altimétricos na qualidade dos MNTs e produtos derivados foi avaliada através da comparação dos próprios modelos, da declividade e do fluxo superficial acumulado.

\section{RESULTADOS}

\section{Influência de diferentes algoritmos na qualidade dos MNTs e produtos derivados}

Para as comparações, os PIs dos MNTs foram sobrepostos com Cur-Cot_25. Média, mínimo e máximo foram calculados para cada PI matricial, o erro máximo e o erro médio quadrático se baseiam nos valores altimétricos ao longo das curvas de nível e nos pontos cotados comparando Cur-Cot_25 e os dois MNTs.

A Tabela 3 mostra os momentos obtidos para os MNTs elaborados com Createtin/Tinlattice e Topogrid em comparação com Cur-Cot_25. Observase que a triangulação convencional resulta em uma elevação média significativamente superior (nível de significância de 0,05 , teste $t$ para amostras correlatas) ao obtido através do algoritmo Topogrid. Os histogramas da freqüência dos valores altimétricos (Figura 2) mostram também que Createtin conserva melhor os valores máximos dos dados primários do que Topogrid. A classe $245-255 \mathrm{~m}$ possui ocorrências somente no caso de MNT_100_tin_c. O máximo maior e o mínimo menor do que obtido em
Tabela 3. Momentos e erros dos MNTs obtidos para modelações com Createtin/Tinlattice e Topogrid ao longo das isolinhas e nos pontos cotados (em metros, 8245 células amostradas).

\begin{tabular}{lccc}
\hline & $\begin{array}{c}\text { Cur- } \\
\text { Cot_25 }\end{array}$ & $\begin{array}{c}\text { MNT_100_ } \\
\text { tin_c }\end{array}$ & $\begin{array}{c}\text { MNT_100_ } \\
\text { top_c }\end{array}$ \\
\hline Média & 177,78 & 177,14 & 174,52 \\
Máximo & 266,00 & 267,94 & 252,41 \\
Mínimo & 146,00 & 136,67 & 152,58 \\
Erro máx. & - & 49,50 & 46,67 \\
Erro médio & - & 13,00 & 11,43 \\
quadrático & & & \\
\hline
\end{tabular}

Cur-Cot_25 (Tabela 3) são causados pela baixa densidade de informações plano-altimétricas e pela utilização de informações de áreas adjacentes na modelação que se encontram fora da própria área de validação.

Mantendo o declive ao longo da rede de drenagem, Topogrid tende a nivelar os extremos do relevo e diminuir depressões locais, fato que se manifesta no mínimo e máximo observado. O erro médio quadrático é significativamente menor (nível de significância de 0,05 ) do que o obtido através da triangulação convencional. A distribuição contínua da freqüência das elevações de Cur_Cot-25 não se repete da mesma forma no caso de MNT_100_top_c e MNT_100_tin_c (Figura 2). Os dois histogramas mostram máximos expressivos nas classes 155$165 \mathrm{~m}$ e 195-205 m. Conforme Wood (1996), esta 


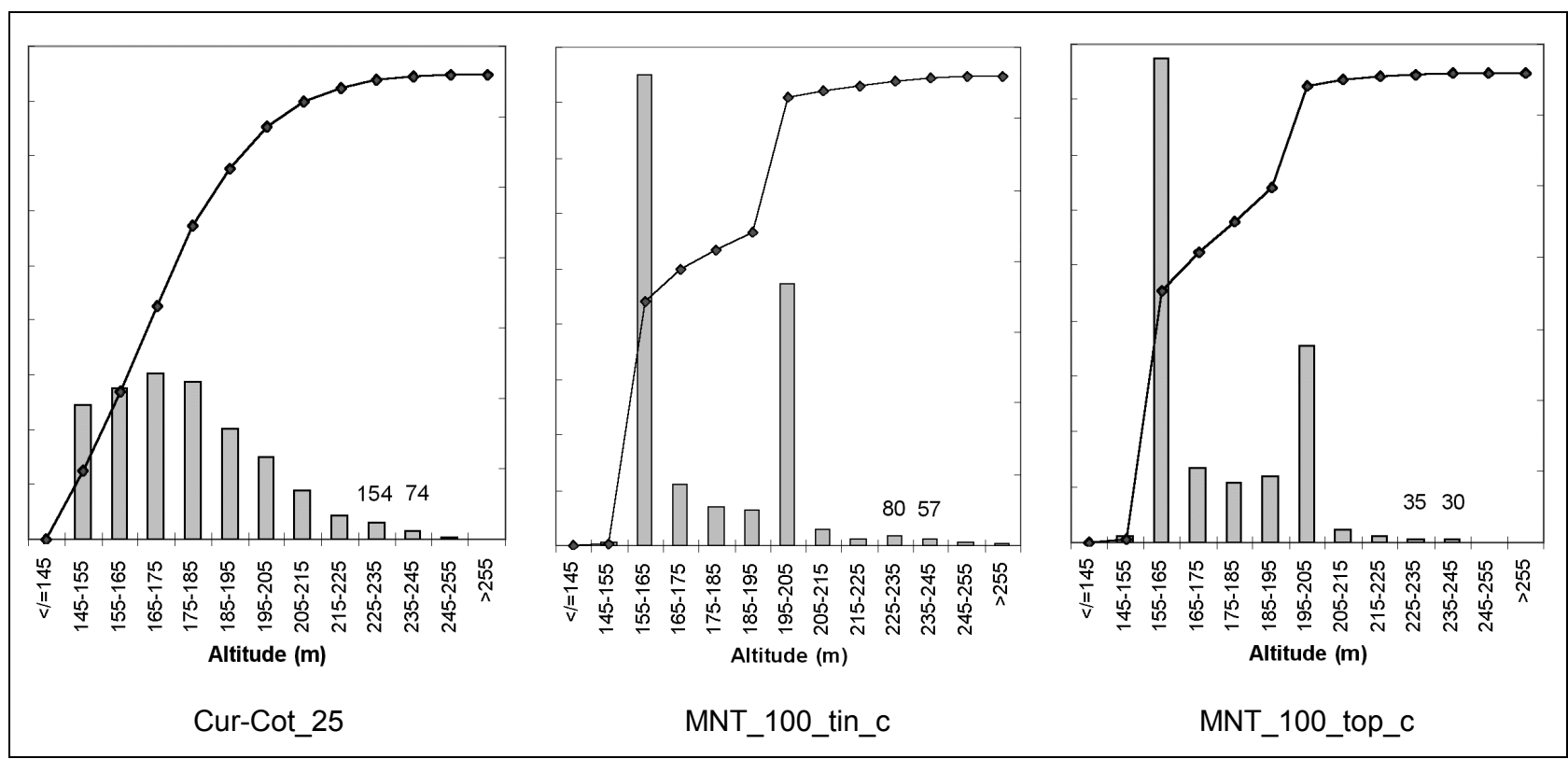

Figura 2. Histogramas da freqüência dos valores de elevação obtidos para Cur-Cot_25 e os modelos MNT_100_tin_c e MNT_100_top_c (resolução horizontal 150 m) ao longo das curvas de nível e nos pontos cotados (n: 8245).

caraterística é causada pelas curvas de nível utilizadas na interpolação, no caso as isolinhas de $160 \mathrm{~m}$ e $200 \mathrm{~m}$ do mapa topográfico 1:100.000. Este efeito é mais expressivo em MNT_100_tin_c do que em MNT_100_top_c. Pela mesma razão (curva de nível de $240 \mathrm{~m}$ ) observa-se uma diminuição da freqüência menos expressiva da classe $225-235 \mathrm{~m}$ para a classe $235-245 \mathrm{~m}$ nos dois MNTs do que no caso de Cur_Cot-25.

A avaliação dos momentos, erros e histogramas não carateriza a distribuição espacial das incertezas dos modelos. A visualização possibilita uma primeira avaliação da qualidade dos MNTs gerados (Figura 3). Na triangulação convencional (MNT_100_tin_c) se manifesta uma tendência de criar áreas completamente planas em regiões com baixa disponibilidade de curvas de nível ou pontos cotados (flechas simples), fato constatado também por Barbalic e Omerbegovic (1999). Nestas áreas, Topogrid modifica os valores da altitude conforme as trajetórias da rede de drenagem (Figura 3, detalhe 1). O algoritmo evita desta forma a interrupção do declive real nos canais.

A interpolação convencional, mesmo utilizando a rede de drenagem como linhas de quebra, produz estruturas artificiais de relevo com trajetórias do rio Cuiabá e de alguns afluentes contra o declive (Figura 3, detalhe 2, flechas sólidas).

Diferenças substanciais entre os dois métodos se manifestam na simulação da rede de drena- gem e do fluxo superficial acumulado. Para a área de estudo e a resolução horizontal dos modelos foi definido que um pixel faz parte da rede simulada se pelo menos 20 outras células deságuam nele (conceito do "limite constante de área" conforme Tarboton et al., 1991). Garbrecht e Martz (1999) salientam que o valor limite para a inicialização dos canais deve ser arbitrariamente estabelecido conforme as caraterísticas da geologia e do padrão da rede de drenagem. Na triangulação convencional determina-se um comprimento total da rede de $259,5 \mathrm{~km}$, enquanto no Topogrid, de $224,5 \mathrm{~km}$. A rede digitalizada dos mapas topográficos (todos os canais representados por linhas simples) possui um comprimento de $218,2 \mathrm{~km}$. Observa-se que a opção de 20 Pixels ainda não reproduz todas as cabeceiras dos afluentes do rio Cuiabá, fato que confirma a superestimação expressiva do comprimento da rede por Createtin/Tinlattice.

A visualização mostra que as trajetórias da rede obtidas através da triangulação convencional (Dre_100_tin_c) não correspondem com a situação real (Figura 4, lado esquerdo).

O leito do rio Cuiabá está deslocado, o canal duas vezes interrompido e a direção do escoamento em dois dos três subtrechos invertida (flechas sólidas). Vários afluentes são fragmentados, outros são criados artificialmente (flechas pontilhadas). Na modelação baseada em MNT_100_ top_c, a rede de drenagem é representada adequa- 


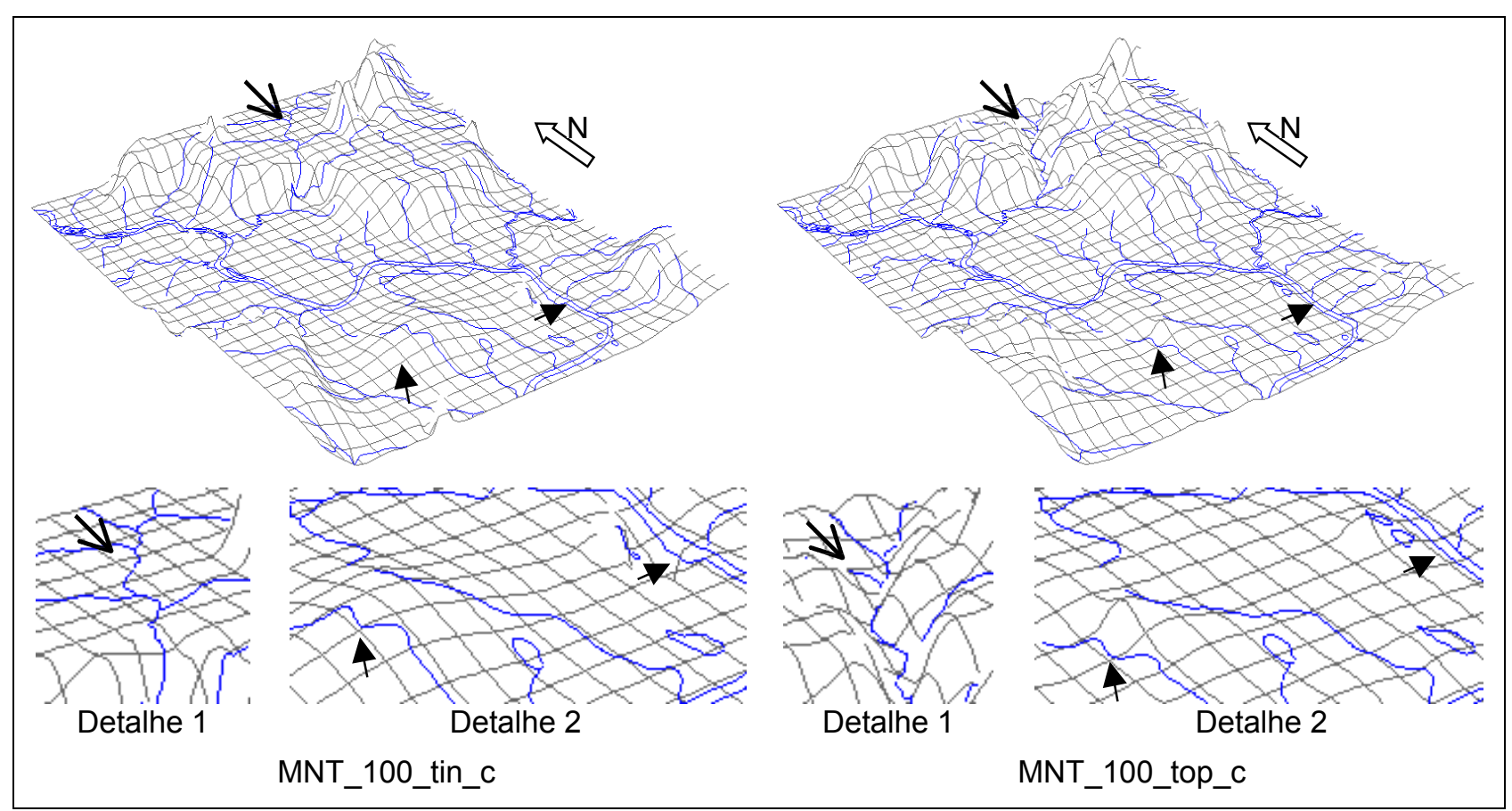

Figura 3. MNTs baseado nos mapas 1:100.000, elaborado através de Createtin-Tinlattice e Topogrid, fator de exageração vertical 15, vista $S W, 15 \times 18 \mathrm{~km}$.

damente. Erros ocorrem somente no caso de alguns afluentes (lado direto, flechas simples). Conforme os resultados obtidos, para as avaliações seguintes foi utilizado somente o algoritmo Topogrid.

\section{Influência da rede hidrográfica como "linhas de quebra" na elaboração de MNTs}

A Figura 5 mostra as redes de drenagem originais (linhas contínuas) e os fluxos superficiais acumulados (células) calculados através de Topogrid a partir do mapa 1:100.000 sem (Fac_100_top_s) e com (Fac_100_top_c) consideração da rede hidrográfica na interpolação. No caso da desconsideração da rede, o curso do rio Cuiabá é uma vez interrompido e a direção do escoamento na seção setentrional invertida (flecha sólida). Observam-se também alguns deslocamentos do leito principal (flechas pontilhadas). A flecha simples mostra que ocorrem também inversões nos afluentes em terreno mais ondulado fora do vale do rio Cuiabá. Todos os erros citados não são observados no experimento que considera as linhas de quebra (Fac_100_top_c).

Um erro médio quadrático dos valores altimétricos de $12,28 \mathrm{~m}$ foi determinado para o MNT modelado sem consideração das linhas de quebra.
Para o MNT modelado considerando as linhas de quebra, o erro foi de $11,43 \mathrm{~m}$, resultado significativamente superior para um nível de significância de 0,05 .

\section{Influência da resolução vertical dos dados plano-altimétricos na qualidade dos MNTs e produtos derivados}

Altimetria - A Tabela 4 mostra momentos, erros máximos e erros médios quadráticos obtidos para os MNTs elaborados com Topogrid baseados nas informações plano-altimétricas e rede de drenagem do mapa topográfico 1:100.000 e da planta urbana 1:25.000 comparados com Cur-Cot_25.

A superioridade de MNT_25_top_c é significativa para as médias e erros médios quadráticos (nível de significancia 0,05). Com base nas informações plano-altimétricas da planta urbana, MNT_25_top_c é evidentemente uma boa aproximação da altimetria ao longo das curvas de nível e nos pontos cotados. Portanto, MNT_25_top_c no total, foi considerado uma aproximação do relevo real na área de validação para as análises a seguir.

A Figura 6 mostra MNT_100_top_c, MNT_ 25_top_c e uma imagem de diferença visualizando os erros entre os dois modelos. No modelo 

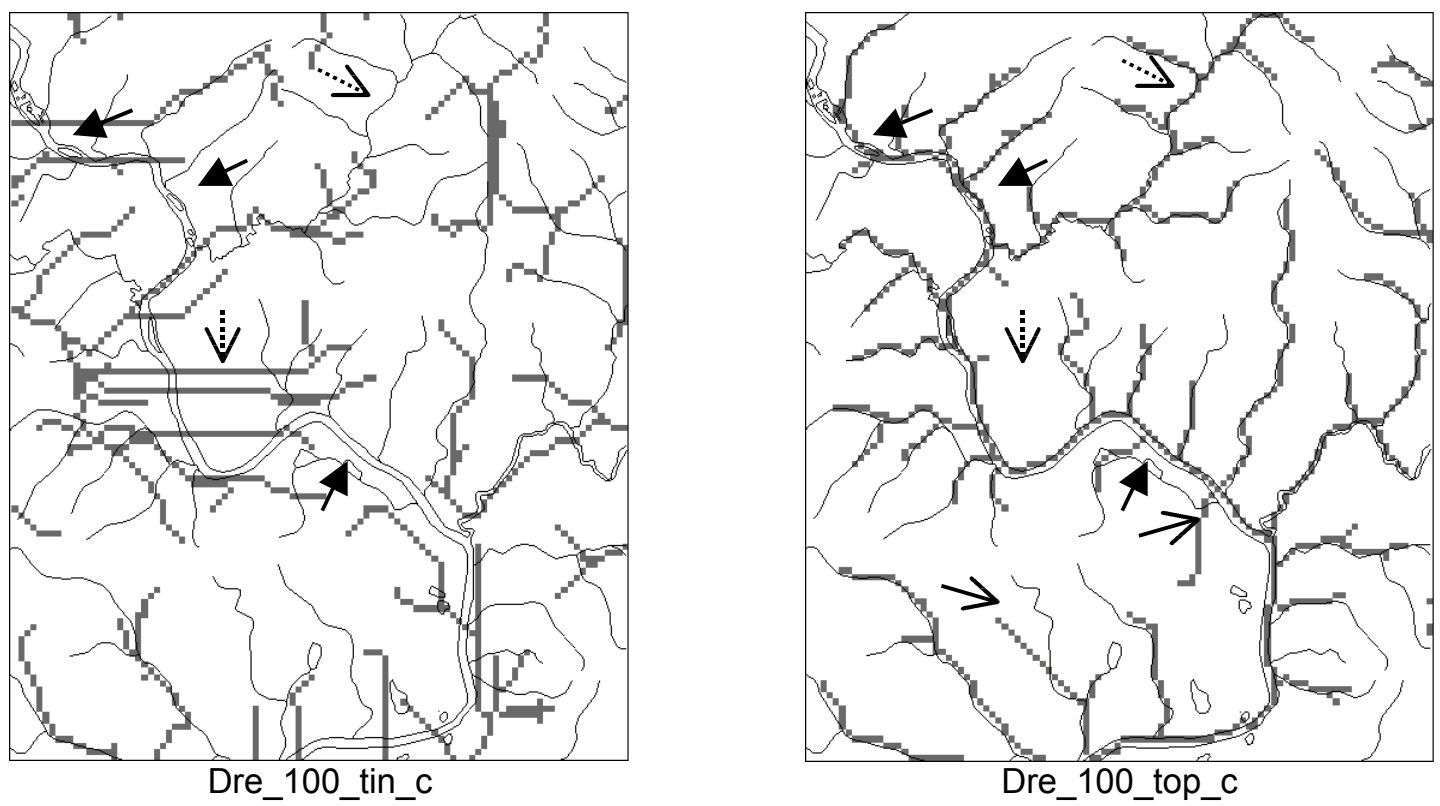

Figura 4. Rede de drenagem real (linhas contínuas) e calculada (células) através de MNT_100_tin_c MNT_100_top_c.

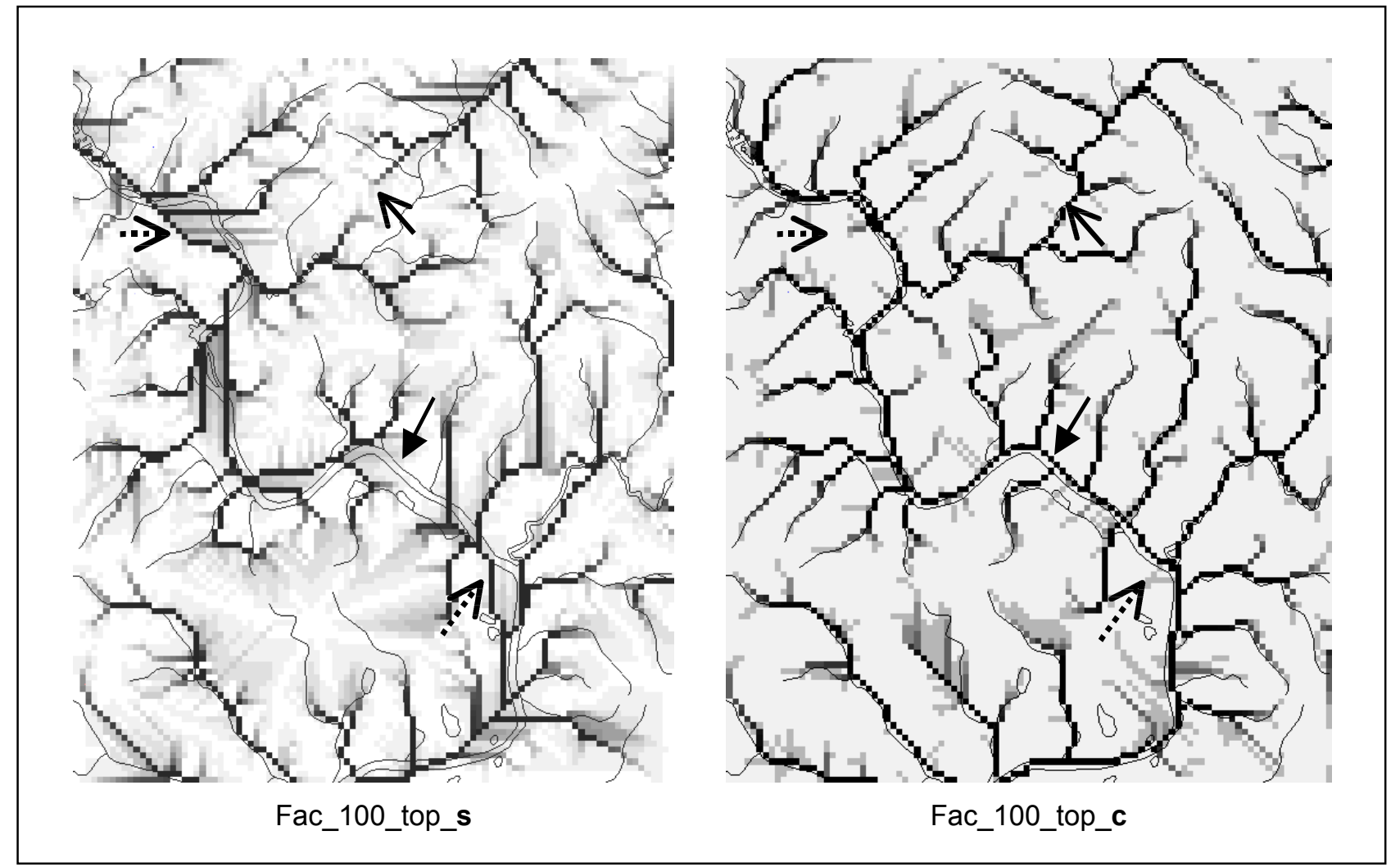

Figura 5. Simulação do fluxo superficial acumulado baseada em MNTs interpolados por Topogrid sem (s) e com (c) utilização de linhas de quebra. 


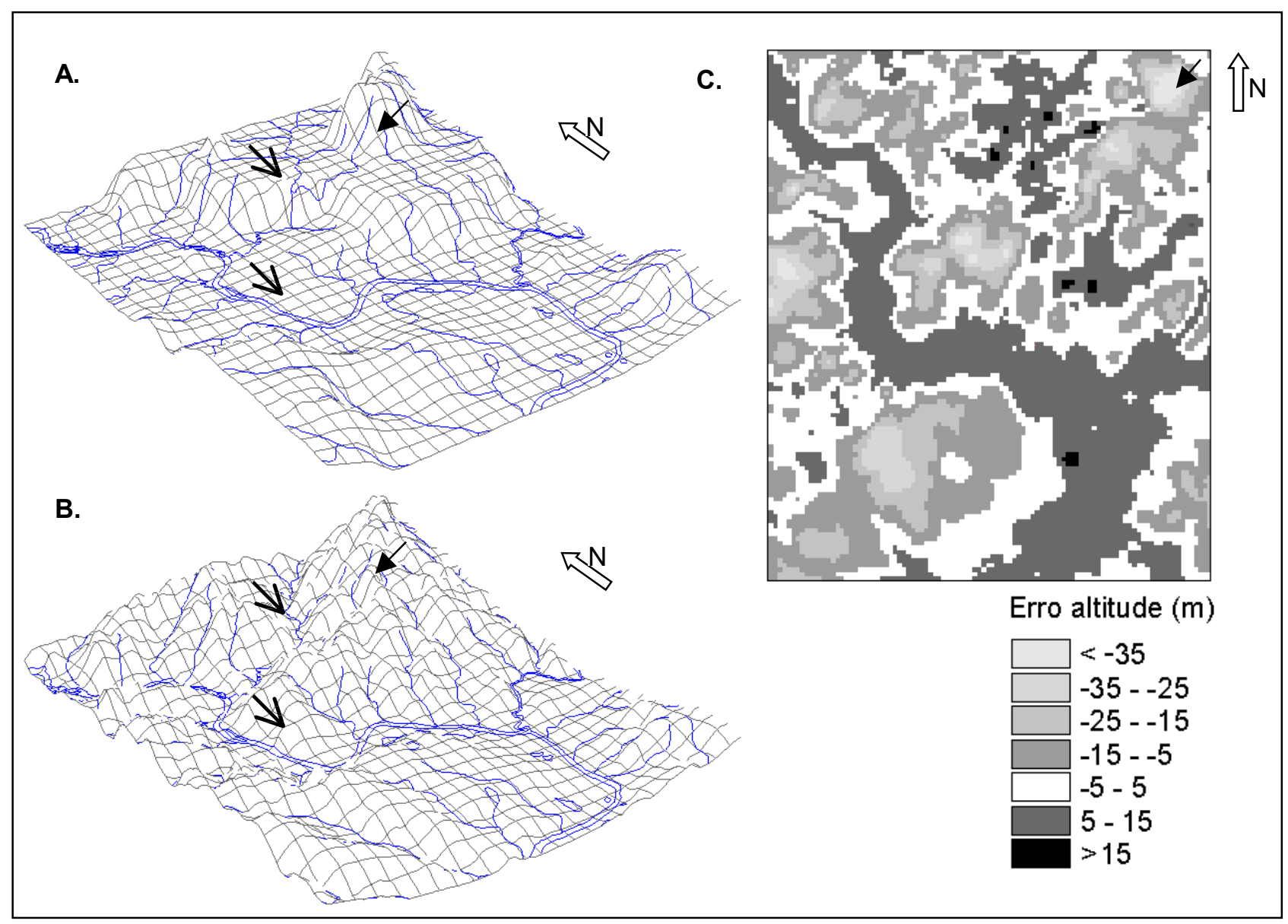

Figura 6. A) MNT_100_top_c, fator de exageração vertical 15; B) MNT_25_top_c, fator de exageração vertical 15; C) PI da diferença entre as elevações dos modelos MNT_100_top_c e MNT_25_top_c (desvios máximos $-47,1 \mathrm{~m}$ e +25,9m).

MNT_25_top_c observa-se um detalhamento maior do relevo causado pela resolução vertical das curvas de nível de $10 \mathrm{~m}$ (40 m em MNT_100_top_c) e maior densidade dos pontos cotados (N $\mathrm{N}_{\text {MNT_25_top_c: }}$ 105 pontos, NMNT_100_top_c: 17 pontos).

Esse fato pode ser associado ao Paradoxo de Steinhaus (Steinhaus, 1960) que descreve o fenômeno que medições de comprimentos aumentam com o aumento da resolução da medição. Em escalas menores, medições de maior resolução não são mais representadas devido ao maior grau de generalização dos mapas. No caso tridimensional de um MNT, os comprimentos de um perfil topográfico ou de curvas de nível simuladas variam em função da resolução vertical.

A grande porcentagem de altitudes com valores próximos das curvas de nível já constatada nos histogramas (Figura 2) se manifesta no modelo MNT_100_top_c em um relevo “terraceado”. Esta caraterística observa-se sobretudo na transição entre o vale do rio Cuiabá e as áreas mais altas do
Tabela 4. Momentos dos MNTs obtidos para modelações com Topogrid baseados nos mapas 1:100.000 e 1:25.000 (em metros, 8245 células amostradas).

\begin{tabular}{lccc}
\hline & $\begin{array}{c}\text { Cur- } \\
\text { Cot_25 }\end{array}$ & $\begin{array}{c}\text { MNT_100_ } \\
\text { top_c }\end{array}$ & $\begin{array}{c}\text { MNT_25_ } \\
\text { top_c }\end{array}$ \\
\hline Média & 177,78 & 174,52 & 177,60 \\
Máximo & 266,00 & 252,41 & 255,93 \\
Mínimo & 146,00 & 152,58 & 145,73 \\
Erro máx. & - & 46,67 & 24,84 \\
Erro médio & - & 11,43 & 3,95 \\
quadrático & & & \\
\hline
\end{tabular}

embasamento da Baixada Cuiabana e nas regiões mais altas no noroeste da área de validação (flechas simples).

Deve ser considerado que os erros verticais não dependem somente da própria estimativa da altitude, mas também do erro planimétrico, causado por incertezas na sobreposição de dois PIs deri- 
vados de duas bases cartográficas (Wood, 1996). Uma validação da qualidade da sobreposição dos mapas 1:100.000 e 1:25.000 em 15 pontos independentes resultou em um erro médio quadrático de $38,3 \mathrm{~m}$. Observa-se portanto que os erros maiores ocorrem em áreas de alta declividade, onde um pequeno deslocamento horizontal pode causar grandes desníveis (Figura 6c, flecha sólida).

Os máximos absolutos dos desvios negativos (altitude maior em MNT_25_top_c) são maiores do que os mínimos absolutos (altitude maior em MNT_100_top_c - Figura 6c). A elevação média de MNT_25_top_c supera a de MNT_100_top_c em $2,60 \mathrm{~m}$. Esse fato se deve sobretudo à maior quantidade de informações altimétricas disponíveis na planta urbana. Em mapas topográficos, cotas altimétricas são registradas nos extremos do relevo. Nas unidades geomorfológicas da área de validação, como na grande maioria de paisagens naturais, depressões fechadas são muito mais raras do que picos (Mark, 1988). Consequentemente, a maioria dos pontos cotados causa uma elevação do relevo em MNT_25_top_c comparado com MNT_100_ top_c. Pela mesma razão a maior resolução vertical causa uma elevação do relevo. No mapa topográfico 1:100.000, as elevações mais altas do que $240 \mathrm{~m}$ não são mais representadas por curvas de nível adicionais, enquanto na planta urbana 1:25.000 ocorrem dois polígonos de $250 \mathrm{~m}$ e um de $260 \mathrm{~m}$.

O vale do rio Cuiabá, portanto, possui desvios positivos. No mapa topográfico 1:100.000, a depressão do vale é representada somente por pontos cotados e a isolinha de $160 \mathrm{~m}$, tendo em boas partes uma elevação de $150 \mathrm{~m}$ (isolinha disponível na planta urbana) ou menor.

Declividade - O "terraceamento" de MNT_100_ top_c aumenta a ocorrência de extremos nos PIs da declividade (Figura 7). Para Dec_100_top_c existem várias células com declives acima de 9\%, 10\% e $11 \%$, classes que não ocorrem para Dec_25_top_c. A classe com declives abaixo de $1 \%$ tem uma freqüência altamente superior à de Dec_25_top_c. A mediana de Dec_25_top_c é significativamente maior (nível de significancia 0,05, teste de Wilcoxon) do que de Dec_100_top_c, fato que pode, por exemplo, resultar em subestimações em modelações da erosão.

Fluxo superficial acumulado - Os dois histogramas das freqüências das classes do fluxo superficial acumulado mostram uma boa correspondên- cia (Figura 8). No PI Fac_25_top_c, as classes das ocorrências 0 e 1 têm uma freqüência superior, enquanto as classes 2-3 e 4-7 possuem freqüência inferior, causadas pela melhor definição do microrelevo acompanhada de uma tendência de concentrar mais rapidamente o fluxo em canais.

Como Topogrid considera as trajetórias da rede de drenagem digitalizada (que varia nas duas bases cartográficas somente em poucos detalhes), constata-se uma boa correspondência nas classes de maior freqüência.

A imagem do módulo da diferença entre os dois PIs do fluxo superficial acumulado Fac_25_top_c e Fac_100_top_c mostra os maiores erros ao longo das linhas de drenagem em áreas de alto acúmulo (Figura 9). Estes desvios não se devem em primeira linha aos erros na própria simulação, mas aos deslocamentos planimétricos na sobreposição dos PIs para fins de validação. Para melhor comparação entre os PIs, as tolerâncias horizontais e verticais disponíveis para a calibração do algoritmo foram zeradas, considerando que estas variáveis modificam ("suavizam") os modelos em geral. As áreas dos interflúvios mostram, em grande parte da área de validação, uma boa correspondência.

\section{DISCUSSÃO}

\section{Influência de diferentes algoritmos na qualidade dos MNTs e produtos derivados}

Na comparação dos momentos (média, mínimo, máximo) dos MNTs obtidos através dos dois tipos de algoritmos testados (Createtin/Tinlattice: triangulação de Delaunay, seguida de uma interpolação quíntica; Topogrid: interpolação localmente adaptada) o algoritmo convencional mostra uma ligeira superioridade ao Topogrid. O erro máximo e o erro médio quadrático da modelação com Topogrid, entretanto, é menor do que os obtidos para a Triangulação/Interpolação convencional. Possuindo erros médios quadráticos abaixo de $15 \mathrm{~m}$ e erros máximos inferiores a $50 \mathrm{~m}$, os dois modelos correspondem com a qualidade exigida pelo U.S. Geological Survey para modelos do nível 1 (USGS, 1997). Este nível mais baixo de qualidade é típico para os MNTs de 7.5' disponíveis nos Estados Unidos que são baseados, como as informações planoaltimétricas dos mapas 1:100.000 brasileiros, em aerolevantamentos de pequena escala. 


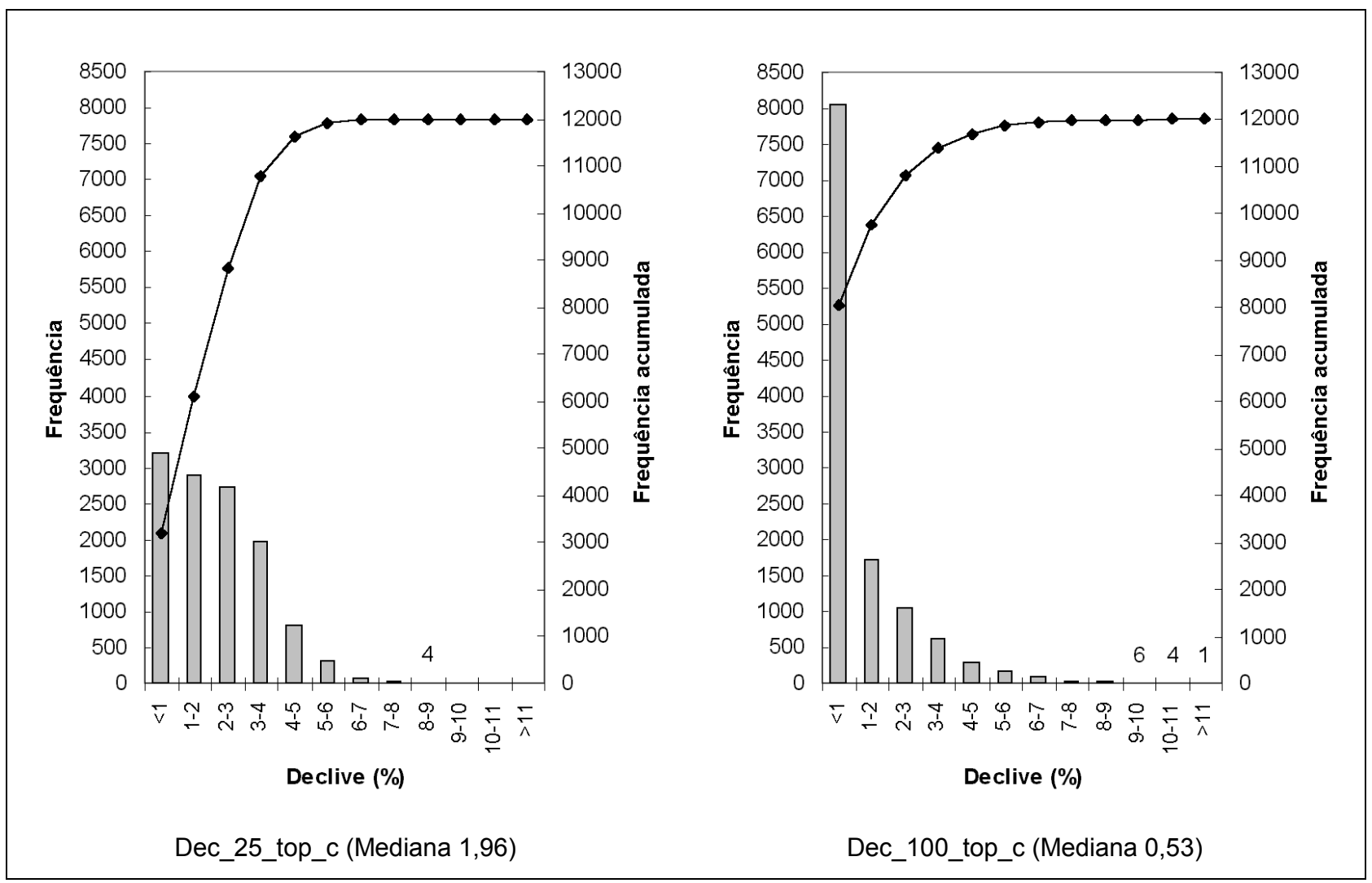

Figura 7. Histogramas da declividade computados para MNT_25_top_c e MNT_100_top_c.

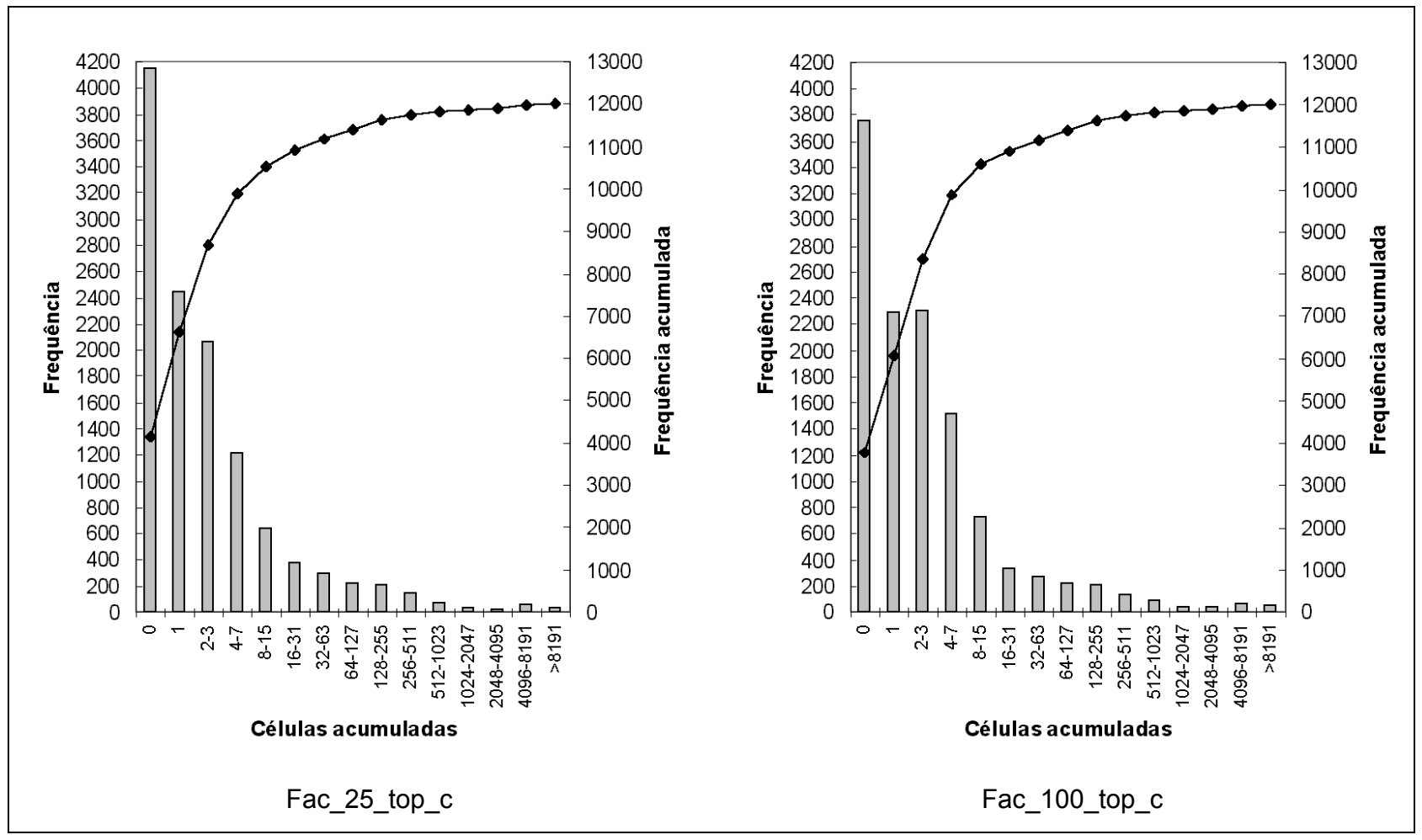

Figura 8. Histogramas do fluxo superficial acumulado computados para MNT_25_top_c e MNT_100_top_c. 


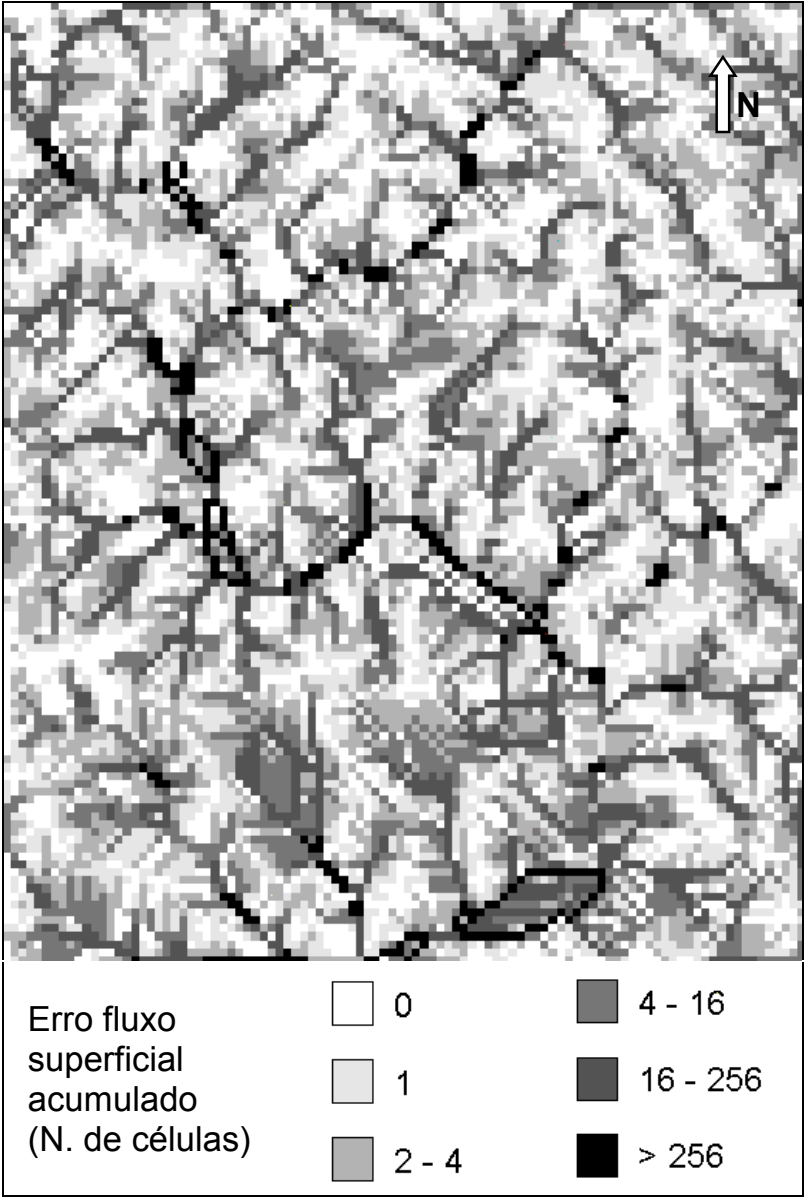

Figura 9. PI do módulo da diferença entre os fluxos superficiais acumulados calculados através de MNT_25_top_c e MNT_100_top_c.

Deve ser considerado portanto, que estes erros tendem a aumentar em áreas com maior faixa de elevação, sobretudo devido a erros planimétricos.

Para uma avaliação da aplicabilidade de MNTs para estudos hidrológicos é fundamental a distribuição espacial das elevações por influenciarem parâmetros fisiográficos como a declividade, direção de escoamento e o fluxo superficial acumulado. Os histogramas da freqüência das altitudes obtidos para os dois algoritmos são caraterizados por máximos expressivos nas classes que incluem as elevações das curvas de nível que ocorrem na área de validação. Na visualização, estas classes correspondem com áreas quase planas ao redor das curvas de nível. Sem considerar a influência da acurácia e resolução dos dados plano-altimétricos primários, essa tendência pode ser relacionada a (Wood, 1996):

i. representação das isolinhas no modelo dos dados do SIG (curvas de nível são armaze- nadas como seqüências de pontos que são interpretados pelos interpoladores como independentes);

ii. uso de interpoladores exatos (que conservam os valores primários de curvas de nível e pontos cotados);

iii. caraterísticas de algoritmos de triangulação (áreas entre duas isolinhas iguais recebem o valor das próprias linhas).

O item (i) é válido para o modelo de dados de Arc/Info; as duas técnicas de triangulação/interpolação utilizam sobretudo isolinhas para a modelação. O "terraceamento" nos modelos é ainda mais expressivo no MNT_100_tin_c, baseado em uma triangulação de Delaunay com a caraterística de reproduzir as altitudes originais das curvas de nível (ii). Na falta de linhas de quebra entre duas isolinhas da mesma altitude, o interpolador quíntico utilizado em Tinlattice cria áreas com a mesma elevação das curvas de nível (compare Barbalic e Omerbegovic, 1999). Topogrid, entretanto, permite a modificação das elevações originais conforme as trajetórias da rede de drenagem (ii), e pode, como interpolador global, assegurar declives determinados em escalas menores do que a escala final (iii).

A superioridade de Topogrid para aplicações hidrológicas se manifesta mais expressivamente na simulação da rede de drenagem e do fluxo superficial acumulado. Várias interrupções e deslocamentos da rede simulada mostram que a técnica convencional não é apropriada para a elaboração destes parâmetros. Saunders (1999) observa variações expressivas na delineação de sub-bacias, operação efetuada a partir de PIs da direção do escoamento superficial. Consequentemente a determinação de parâmetros associados às sub-bacias tais como área ou tempo de retenção (Olivera et al., 1998) deveria ser preferencialmente baseada em modelações com Topogrid ou algoritmos similares.

\section{Influência da rede hidrográfica como "linhas de quebra" na elaboração de MNTs}

Os resultados obtidos mostram a importância fundamental da utilização de linhas de quebra no processo das modelações dos MNTs objetivando aplicações hidrológicas. É importante observar que a utilização de linhas de quebra em algoritmos de triangulação convencional (Createtin) não é equivalente a uma imposição da direção de escoamento ao 
longo da rede de drenagem como efetuada através de Topogrid ou em algoritmos de recondicionamento do tipo "stream burning" ("queimar rios") (Saunders e Maidment, 1996; Saunders, 1999).

Para melhoria dos MNTs provenientes da missão SRTM (DLR, 2000), prevê-se, portanto, a necessidade da integração da rede de drenagem pré-processada. Saunders (1999) mostra que a rede deve ser representada por linhas simples, sem bifurcações e que lagoas devem ser removidas dos PIs da hidrografia.

\section{Influência da resolução vertical dos dados plano-altimétricos na qualidade dos MNTs e produtos derivados}

A comparação dos momentos e erros dos MNTs elaborados pelas duas bases cartográficas mostram, como era de se esperar, uma grande superioridade de MNT_25_top_c. Os resultados devem ser, entretanto, interpretados somente qualitativamente, considerando que a base de comparação são as elevações ao longo das curvas de nível que são também utilizadas para a modelação do MNT_25_top_c.

A avaliação da distribuição espacial dos erros (MNT_25_top_c interpretado como relevo real), mostra que uma resolução vertical reduzida tende, no interpolador utilizado, a nivelar as elevações extremas do relevo. Como observam-se os erros maiores em áreas de relevo acidentado, prevê-se um aumento dos erros em relevos mais acentuados.

Autores como Garbrecht e Martz (1999) salientam que maiores resoluções horizontais influenciam positivamente os resultados em modelações de parâmetros fisiográficos derivados. A "aplanação" e o "terraceamento" observados em MNT_100_top_c e MNT_100_tin_c reamostrados pelo interpolador para uma resolução horizontal de $150 \mathrm{~m}$, mostram que em relevos pouco acidentados a resolução deveria ser reduzida ou pelo menos que um aumento seria incompatível com a resolução vertical e a qualidade dos dados plano-altimétricos provenientes dos mapas topográficos 1:100.000. Wood (1996) salienta que estes efeitos podem somente ser diminuídos através do acréscimo de informação plano-altimétrica primária (curvas de nível, linhas de quebra). Neste contexto deve ser considerado que o algoritmo Topogrid é apropriado para modelações em situações com uma relativa escassez de dados plano-altimétricos (ESRI, 1998b).
As limitações observadas para o modelo baseado em dados de resolução reduzida, se manifestam em modificações na freqüência e distribuição espacial dos parâmetros declividade e fluxo superficial acumulado (Gyasi-Agyei et al., 1995). Foi observada uma diminuição do declive médio no modelo de menor resolução vertical, caraterística também constatada por Wang e Yin (1997) e Zhang e Montgomery (1994). Ao contrário de Wang e Yin (1997), neste estudo um declive máximo maior foi observado para um MNT de menor resolução vertical (MNT_100_top_c), fato causado pelo já mencionado efeito de "terraceamento" na resolução horizontal escolhida. Os histogramas dos fluxos superficiais acumulados mostram uma boa correspondência das frequiências obtidas para os dois modelos comparados. Grandes diferenças na sobreposição dos PIs do fluxo superficial são causadas primordialmente por pequenos deslocamentos horizontais da rede hidrográfica. Em uma comparação de modelos das escalas 1:24.000 e 1:250.000, Wang e Yin (1997) constatam uma boa correspondência no cálculo do fluxo superficial nas duas escalas.

Conclui-se portanto que os dados planoaltimétricos dos mapas topográficos 1:100.000 avaliados são apropriados para a elaboração de MNTs objetivando estudos hidrológicos. Em áreas com relevo pouco acentuado é altamente indicada a utilização de algoritmos com a capacidade de considerar o relevo da área de estudo como um todo, tais como Topogrid (computacionalmente uma técnica local que tem caraterísticas de uma técnica global) ou técnicas globais como krigagem ou splines.

\section{REFERÊNCIAS}

BARBALIC, D. e OMERBEGOVIC, V. (1999). Correction of Horizontal Areas in Tin Terrain Modeling Algorithm. In: ESRI International User Conference, July 26 - 30, 1999, http://www.esri.com/library/ userconf, consulta em abril de 2000.

DLR (2000). X-SAR/SRTM STS-99 - Mission Status Report, 22 de Fev. 2000 (http:/ /www.dlr.de/oeffentlichkeit /specials/sonderseiten/srtm), consulta em fevereiro de 2000.

ESRI (1998a). Arc/Info para NT, Versão 7.2.1.

ESRI (1998b). Online Documentation, Arc/Info 7.2.1.

GALANT, J. C. e HUTCHINSON, M. F. (1996). Towards an Understanding of Landscape Scale and Structure. In: Proceedings of Third International Conference/Workshop on Integrating GIS and 
Environmental Modeling, Santa Fe, NM, January 21-26, http://www.ncgia.ucsb.edu/conf, consulta em abril de 2000

GARBRECHT e MARTZ (1999). Digital Elevation Model Issues in Water Resources Modeling. In: ESRI International User Conference, July 26-30, 1999, http://www.esri.com/library/userconf, consulta em abril de 2000

GUTH, P. L. (1995). Slope and aspect calculations on gridded digital elevation models: examples from a geomorphometric toolbox for person computers. Zeitschrift für Geomorphologie, Supplementband, 101, 35-52.

GYASI-AGYEI, Y., WILLGOOSE, G. e DE TROCH, F. P. (1995). Effects of vertical resolution and map scale of digital elevation models on geomorphological parameters used in hydrology. Hydrological Processes, 9, 363-382.

HUTCHINSON, M. F. (1989). A new procedure for gridding elevation and stream line data with automatic removal of spurious pits. Journal of Hydrology, 106, 211-232.

HUTCHINSON, M. F. (1996). A locally adaptive approach to the interpolation of digital elevation models. In: Proceedings of $3^{\text {rd }}$ International Conference/Workshop on Integrating GIS and Environmental Modeling, Santa Fe, January 21-26, http://www.ncgia.ucsb.edu/conf, consulta em abril de 2000.

JENSON S. K. e J. O. DOMINGUE (1988). Extracting Topographic Structure from Digital Elevation Data for Geographic Information System Analysis. Photogrammetric Engineering and Remote Sensing, 54, 1593-1600.

LEE, J. (1996). Digital elevation models: Issues of Data Accuracy and Applications. In: Proc of the ESRI User Conference 96 http://www.esri.com/libary/ userconf/, consulta em abril de 2000.

LEE, J.; SNYDER, P. K. e FISHER, P. F. (1992). Modeling the effect of data errors on feature extraction from digital elevation models. Photogrammetric Engeneering and Remote Sensing, 58, 1461-1467.

MARK, D. M. (1988). Network Models in Geomorphology. In Anderson, M. G. (ed.) Modeling in Geomorphologic Systems. John Wiley, Chichester, 73-96.

MENDES, C. A. (1996). Integração de modelos hidrológicos e sistemas de informações geográficas: fundamentos. $R B R H, 1,47-66$.

MÜLLER-WOHLFEIL, D.-I., LAHMER, W., KRYSANOVA, V. e BECKER, A. (1996). Topograhybased hydrological modelling in the Elbe drainage basin. In: Proc. of the $3^{\text {rd }}$ International Conference on GIS and Environmental Modeling, Santa Fe, New Mexico, http://www.ncgia.ucsb.edu/conf/, consulta em junho de 2000.

OLIVERA, F., REED, S. e MAIDMENT, D. (1998). HECPrePro vol. 2.0: An ArcView Pre-Processor for HEC's
Hydrologic Modeling System. ESRI User's Conference July 25-31, 1998, San Diego, California, http:// www.crwr.utexas.edu/ gis/gisenv98/, consulta em abril de 2000.

QUINN, P., BEVEN, K., CHEVALLIER, P. e PLANCHTON, O. (1992). The prediction of hillslope flow paths for distributed hydrologic modelling using digital elevation models. In: Beven, K. J. \& Moore, I. D., Terrain Analysis and Distributed Modelling in Hydrology, John Wiley \& Sons, New York, 63-83.

SAUNDERS, W. (1999). Preparation of DEMs for Use In Environmental Modeling Analysis. ESRI International User Conference - July 26-30, 1999, http:// www.esri.com/library/userconf/, consulta em abril de 2000.

SAUNDERS, W. e MAIDMENT, D. (1996). A GIS Assessment of Nonpoint Source Pollution in the San Antonio-Nueces Coastal Basin. Center for Research in Water Resources, Online Report 96-1, University of Texas, Austin.

STEINHAUS, H. (1960). Mathematical Snapshots. London: Oxford University Press.

TARBOTON, D. G.; BRAS, R. L. e RODRIGUES-ITURBE, I. (1991). On the extraction of Channel Networks from Digital Elevation Data. Water Resources Research, 5, $81-100$.

U.S. Geological Survey - USGS (1997). Standards for Digital Elevation Models. National Mapping Program, Technical Instructions.

U.S. Geological Survey - USGS (1999). Map Accuracy Standards. Fact Sheet FS-171-99.

WANG, X. e YIN, Z.-Y. (1997). An evaluation of Using ArcInfo to Extract Basin Physiographic Parameters from DEMs. ESRI User Conference 97, http:// www.esri.com/libary/userconf/, consulta em junho de 2000.

WISE, S. M. (1998). The effect of GIS interpolation errors on the use of DEMs in geomorphology. http:// www.geog.port.ac.uk/geocomp/geo98/, consulta em abril de 2000.

WOOD, J. (1996). The Geomorphological Characterisation of Digital Elevation Models. Ph.D. Thesis, Department of Geography, University of Leicester, UK.

ZHANG, W. H. e MONTGOMERY, D. R. (1994). Digital elevation model grid size, landscape representation and hydrologic simulation. Water Res. Research, 30, 1019-1028. 


\title{
Modeling of Terrain and Hydrographic \\ Parameters in the Cuiabá Watershed
}

\begin{abstract}
This study evaluates the applicability of the Brazilian 1:100.000-scale topographic maps to model terrain and hydrographic basin parameters, such as slope and accumulated flow. The influence of different triangulation/interpolation techniques, the utilization of digital line graphs of the hydrographic network and the vertical resolution of map hypsography on parameter quality are assessed by comparison with data layers based on high resolution map data (1:25.000).
\end{abstract}

Key-words: model; terrain; Cuiabá. 